\title{
Smart Bridge between Railway Platforms
}

\author{
P. Venkata Sai \\ Student \\ Kalsalingam Academy of \\ Research and Education, \\ Krishnankoil,Tamil Nadu
}

\author{
M. Sai Harsha \\ Vardhan \\ Student \\ Kalasalingam Academy of \\ Research and Education \\ Krishnankoil,Tamil Nadu
}

\author{
K. Harsha Vardhan \\ Kiriti \\ Student \\ Kalasalingam Academy of \\ Research and Education \\ Krishnankoil,Tamil Nadu
}

\author{
G. Karthy \\ Assistant Professor \\ Kalasalingam Academy of \\ Research and Education, \\ Krishnankoil, Tamil Nadu
}

\begin{abstract}
This project presents you the detailed explanation about the automatic railway platform. Normally for crossing the railway tracks we use the staircase bridges. In critical times in order to catch our train which is on another platform we go by the bridges. Sometimes we may miss the train by going through it especially elderly people or handicapped people. So, to eradicate that problem we have proposed this system. By sensing the occurrence of the train a moveable platform will connect the platforms. We have used IR sensor and ultrasonic sensor for sensing the occurrence the train. And Wi-Fi module for communication purpose which is connected to the NodeMcu(micro-controller-unit).
\end{abstract}

\section{Keywords}

IR Sensor, Ultrasonic Sensor, WIFI Module, NODEMcu

\section{INTRODUCTION}

In India so many people are travelling through the trains because it is cheapest way for transport. Daily so many old people and physically disabled people also travelling for them stair case is difficult to reach from one platform to another platform. This idea is arranging the movable bridge for easy travelling from one platform to another platform. In most of the villages there is no stair case from $1^{\text {st }}$ platform to $2^{\text {nd }}$ platform. At that time people are crossing through railway tracks. Old people and physically disabled people are facing many problems at that time. For that purpose only we introducing this automatic bridge between railway platforms using Node Mcu(micro-controller-unit).

\section{LITERATURE SURVEY}

By the design of the automatic bridge between the railway platforms using node mcu will reduce the effort for the senior citizens and also for the handicapped people to climb the stairs in the railway station. they will cross through the bridge present between the platforms.

When the train is not in the station the sliding platforms will open and also Barra gates will open for the passengers to cross the platforms. When the train is present in the station the Barra gates and sliding platform is also closed no passenger will cross the platform at that time. They arranged the buzzer also for alerting the people who crossing the platform at the time when the train is coming to the station. They created the green and red lights also for alerting the people who cannot hear the sounds. Green light for travel through the platform and red light indicates the Barra gates are closing no one should not pass through the platforms[1][6]. There is a robot that follow the line. That line will be indicated in the white with black surface or black line with white surface. There are two sensors proximity sensor and IR sensor. The Proximity sensor for direction and IR sensor for obstacle detection. These sensors are arranged on the front end of the robot. It also contains IR-LED and photodiodes are arranged to the motor for on and off the transistors. When the white surface detected the photodiodes decreased and leads to voltage drop the photodiodes are increased for the conduction of transistors so the motor will rotate and start moving. When the black line detected the photodiodes are increased the motor will stop moving[2]. IR sensor is arranged at two places in the station first sensor is arranged at the train arrival point when sensor detected it pass signal to the microcontroller. The micro controller alert the buzzer and led system and also close the bridge. When another sensor detected it open the bridge and also give led signal to move on bridge. It also contain the piezoelectric sensor arranged below the platform to generate the electricity and give to the station domestic appliances like fans, tube lights etc[3]. The mobile platforms are used to travel between the tracks. Those are transmitted the data from the sensors to the microcontroller with the help of the 8051 processor and also they used zig bee technology for transmitting the data[4]. According to the train timings the mobile bridge is open and closed through the automation process[5]. The RF receiver is connected to the train and transmitter to some away from the platform when the transmitter transmit the data there will be no bridge between the platforms[7].In some stations there are line following robots those robots are travelling through the color indication of the line when they detect the black color it start moving when the color changes to white it stop moving[8]. The Escalators are used to move from one platform to another platform for moving we need to use the stepper motor[9]. In some places RF id tags are used to detect the train position for open and close the mobile bridge on tracks[10]. WILD sensor is used to detect the train and send the information to the microcontroller for open and close the bridge on tracks[11]. At the platform only sensor is arranged when the sensor does not detected the platform will open other wise it is closed[12]. Some trains having a system that can control the train through the satellite the train GPRS systems are connected through the satellite. With that information they are giving information to next station when they reach the previous stations[15]. The IR sensors are used to detect the train arrival and departure from the station sensor detect the train and send the voice message to the station for alert the passengers to move away from the platform[13]. The IR sensor and is used to detect the train arrival and departure too and fro from the station it intimate the information of train to the microcontroller ATmega $89 \mathrm{c} 15$. The dc motor is used to lift the bridge[18]. The audio system is used to alert the people on the bridge when the motion sensor detects the bridge is closed other wise it is open[14]. The barre gates are used to send the people from one platform to another when 
the train is not in the platform[16]. Satellite is used to control the train where to stop and where to start. It is fully controlled by the satellite there will be no interaction with the humans while starting and stopping[17][19]. According to the train location by using maps the bridge is open and close with help of the satellite communication[20].

\section{TOOLS USED}

\subsection{Ultrasonic Sensor}

Ultrasonic sensor[21] contains four pins that pins are Vcc, Triger, Eco, GND. Trigger and the ECO pins are mainly used in the Arduino connection there is sending the data to the Arduino. The Arduino is receiving the data through the ECO and Trigger pins. The Vcc pin is connected to the $5 \mathrm{v}$ Arduino pin. GND is connected to the Arduino GND. the Trigger and ECO pins are the output pins of the sensor.

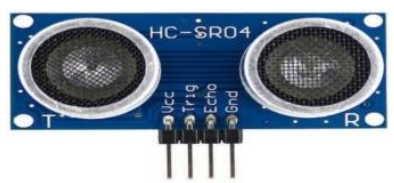

Fig 1: Ultrasonic Sensor

\subsection{IR Sensor}

IR sensor[22] is mainly used for detection and also calculating the length between the sensor and object. It detect the thin object also like cotton. In IR sensor there are two parts one is receiver and another is transmitter. In this there are two type active sensor and passive sensor. Active sensor contains two parts LED and receiver. When the object come near to the sensor the LED reflect the light and it detected by the receiver. The active sensor can also work as proximity sensor. Passive sensor only detect the radiation that does not emitted from the LED.

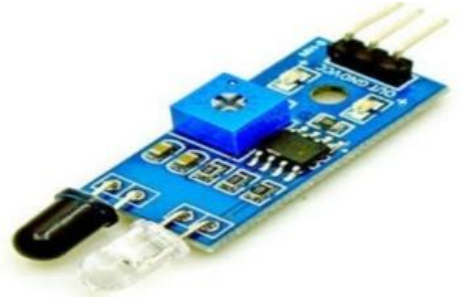

Fig 2: IR Sensor

\subsection{NODEMcu (Micro Controller Unit)}

NODE Mcu[23] is low cost working micro controller with WI-FI module. It is a open source firmware based on ESP8266 WI-FI SoC. Initially it runs on the ESP8266. It is a 32 bit micro controller. It is a single board micro controller having a memory of 128 kilobytes. The storage is 4 Mbytes. Initially it supports the ESP12 later it supports to ESP32 of ESP8266. It is a WI-FI soc integrated with a ten silica Extensa LX106 core used in the IOT applications. This micro controller can also control through the third part apps like blink with the secure and password protected. It contains 13 pins the $0^{*}$ pin is used as the GPIO read/write. The controlled works like Arduino the software used in this is Arduino IDE.

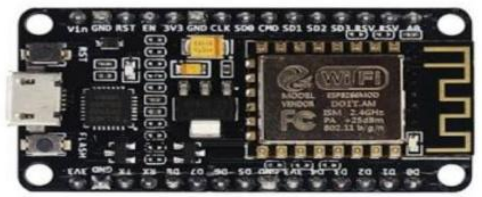

Fig 3: Node MCU

\subsection{WI-FI Module in Node MCU}

WI-FI module[24] is an self contained Soc with an TCP/IP protocol it gives an control access to the WI-FI network. It is capable of an hosting or off loading an network from the another application. It can also program from an AT command firmware. It does not capable for an 5-3v logic shifting. It require an external logic converter.

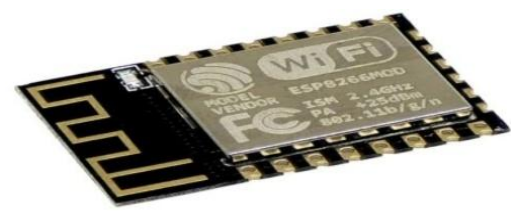

Fig 4: WI-FI Module

\section{SYSTEM ARCHITECTURE}

The total setup is working with the help of the microcontroller Node MCU. Basically Node MCU is similar to Arduino. There is small differences in pins and also having less memory compared to Arduino. We are connecting the ultrasonic sensor and IR sensor to the NodeMcu. NodeMcu is having the inbuilt WI-FI module. For data transmitting WI-FI modules is arranged at both sides of the station ends for detecting the arrival and departure of the train to the station. When they detected they send the data to NodeMcu for arranging the bridge between the platforms. There is an OLED screen for displaying where bridge is removing or not between the platforms. The dc motors are used to move the bridge

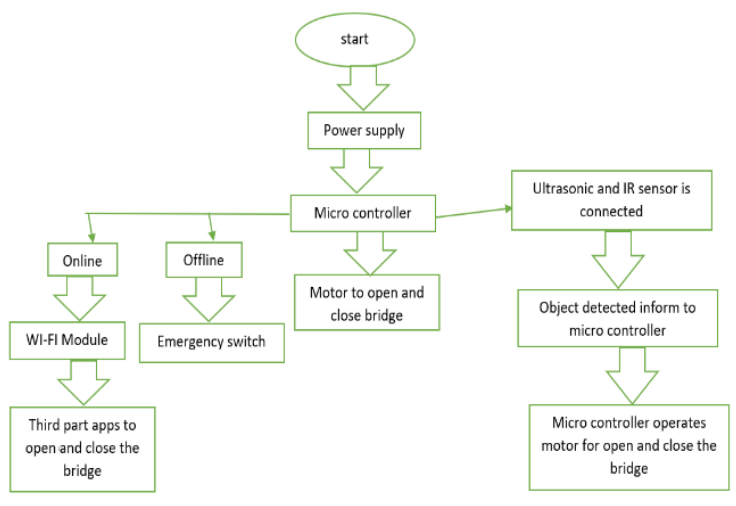

Fig 5: Work Flow

\section{METHDOLOGY}

The figure 6 as block diagram gives the idea of circuit. Arranging ultrasonic sensor and IR sensor at both ends of the stations. Both the sensors are placed at some distances between them when both the sensors are detected only they remove the bridge between the platforms. When the ultrasonic sensor detected it display the train is arrival at the led screen and warn the passengers on the bridge move fast the bridge is removing. The IR sensor detected the bridge is removed. In railway stations there are two tracks between platforms when the train is on the second track the will not remove on the first track similarly when the train is on the first track the bridge will not remove on the second track the passengers can move to first platform and second platform. The ultrasonic and IR sensor send the information through the WI-FI module to Node MCUs WIFI module. The dc motor attach and detach the bridge between the platforms. Bridges can also control through IOT application app. The bridge is worked manually with the help of WI-FI only. The WI-FI is having password that is only available at station master or high superior officer 
in the railway station. When the train is between the platforms they can travel easily by this method.

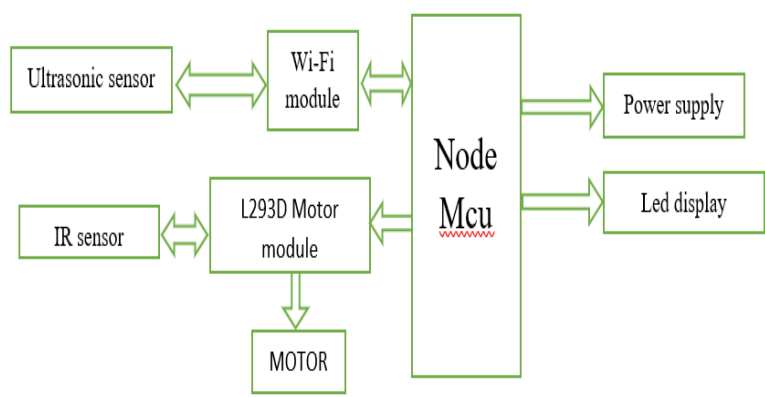

\section{Fig 6: Block Diagram}

\section{RESULTS}

The below diagram shows the connection of the entire setup of the project in proteus. There are total three leds led 1 is indicated when the train is arriving. Led 2 indicates that the bridge is closed. Led 3 is indicated the bridge is opening. In the display screen it shows the train arriving, bridge is opening and bridge is closing. Those are seen in the below figure 8, 9 and 10 .

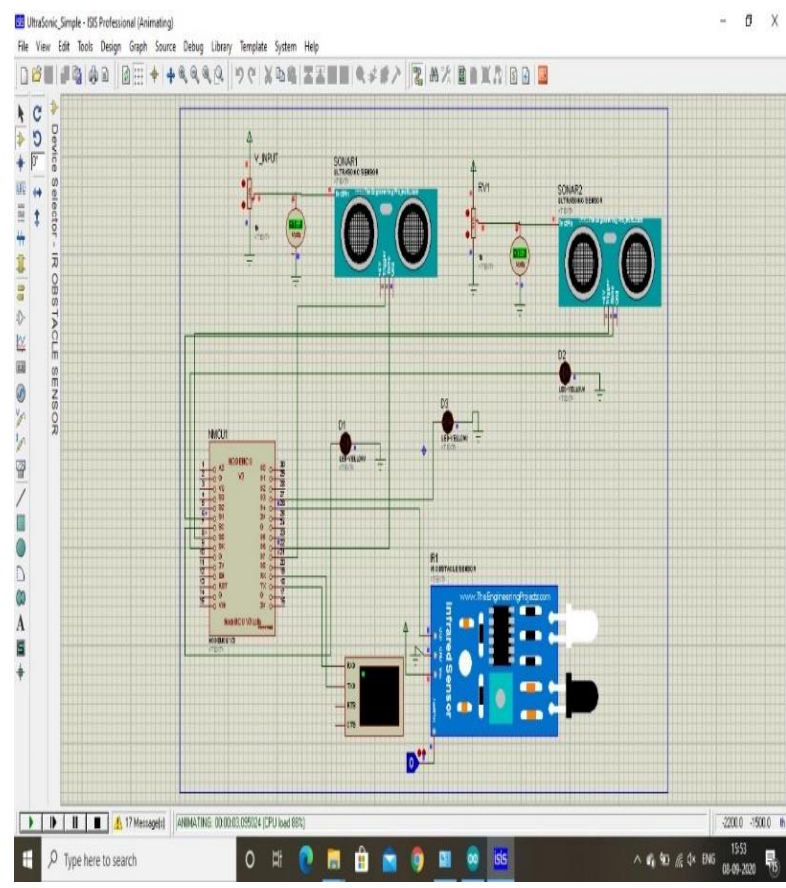

Fig 7: Software Design

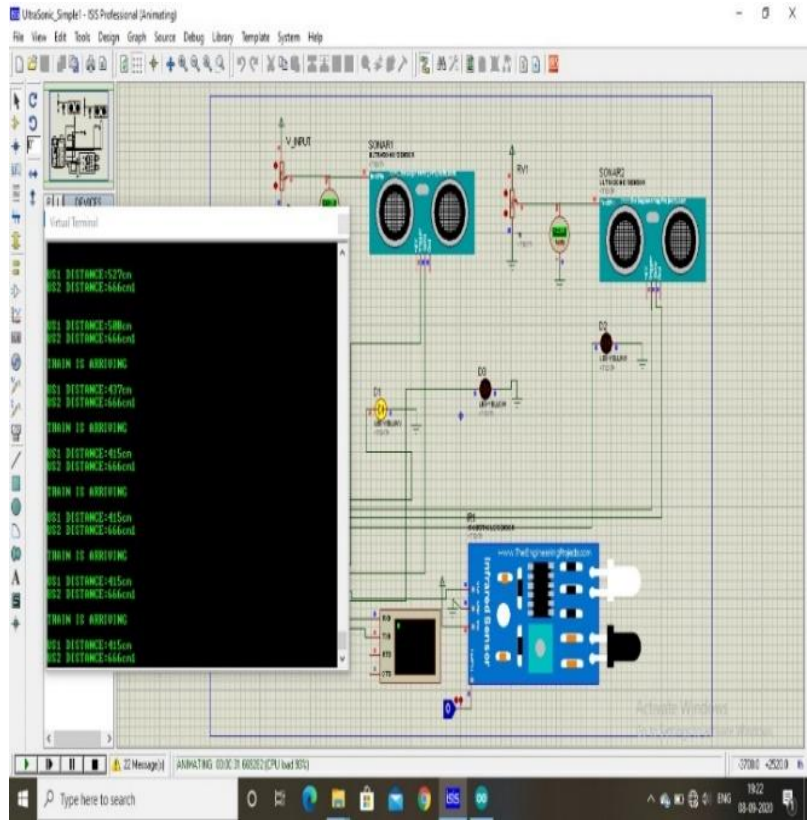

Fig 8: OUTPUT 1

In the figure 8 the led 1 is turn on and displays a message as train is arriving and also display that at what distance the train is from the station.

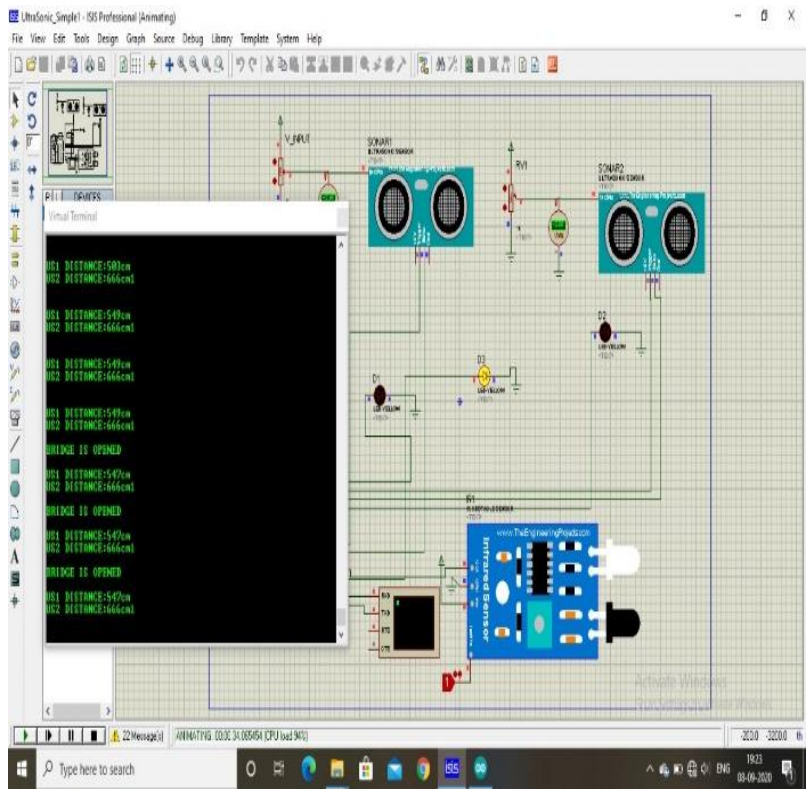

Fig 9: OUTPUT 2

In figure 9 the led 3 is turn on and displays a message the bridge is open. 


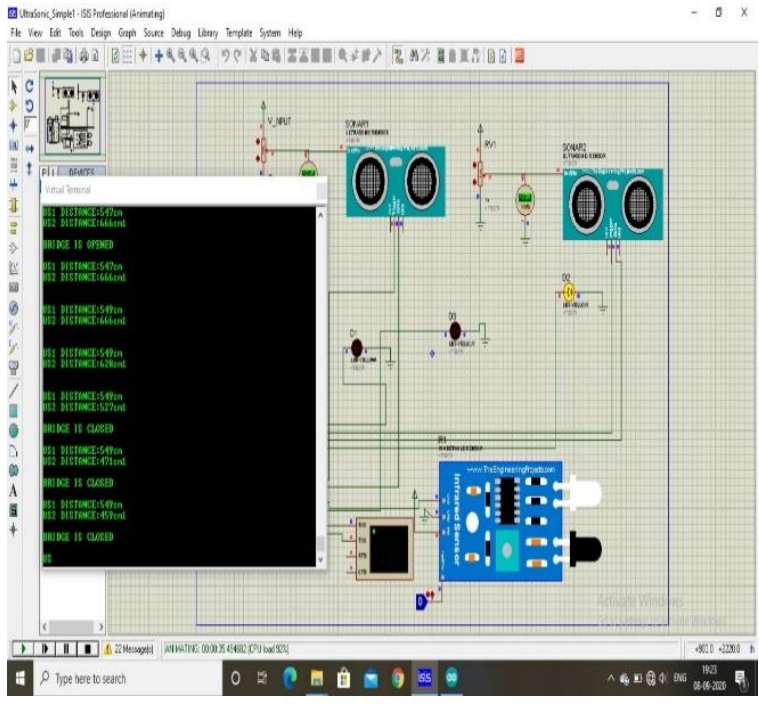

Fig 10: OUTPUT 3

In figure 10 the led 2 is turn on and display a message that bridge is closed.

\section{CONCLUSION}

The main aim of the project is to help the old people and handicapped people to cross the platform without any problem. The cost of the project is less compared with the stair case, elevator and escalator. Through this we can also alert the people in the station of the train arrival. We can easily cross the bridge with less effort. By using the WI-FI, micro controller, sensor and led it can easily open or close the bridge. In case of any failure in the automation there will an automatic switch to open the bridge. The total data is trans mitted through wireless for that wifi module is used to send and receive the information of train arrival and departure to the station that information is displayed in oled screen for alert people on the bridge. The color leds also used for not audible people. WI-FI is completely password protected that password is having with the higher official in the station or with the station master for the small village railway stations.

\section{REFERENCES}

[1] Dr.P.Gomathi, Dinesh "Automatic mobile platform for physically challenged people in railway junction" issue on April-June 2016

[2] Sudarsan .P, Ram Kumar. S, Surendar.R, UdaySankar. T, Karthik "Artificial railway platform for domestic railway station" proceedings of 21st IRF International Conference, 15th March 2015, Chennai, India, ISBN: 978-93-82702-78-8.

[3] Prashantha B, Harisha S "Smart railway crossing embedded with automated platform bridge" issue on August 2015 by IJRET in 2321-730.Engineering and Technology eISSN: 2319-1163.

[4] G.Prabhavathi, B.Sanjana, S.P.Dhivya"Railway track pedestrian crossing between platforms" IOSR Journal of Electronics and Communication Engineering (IOSRJECE) e - ISSN: 2278-2834, p- ISSN: 22788735.Volume 9, Issue 2, Ver. III (Mar - Apr. 2014), PP 87-91.

[5] J. Banuchandar, V.Kaliraj, P.Balasubramanian, S.Deepa, N.Thamilarasi "Automated unmanned Railway Level Crossing System", International Journal of Modern
Engineering Research (IJMER) www.ijmer.com Vol.2, Issue.1, Jan-Feb 2012 pp-458-463 ISSN: 2249-6645.

[6] Polivka A, Fillip A .Satellite-based positioning for CBTC. In: Proceedings of 2nd international conference on Reliability, safety and diagnostics of transport structures and means, Pardubice, 2005.

[7] US. Department of Transportation, Federal Highway Administration. Motor Vehicle Accident Costs (Technical Advisory T7570.2, 31 October).

[8] Silla, A. and J. Luoma (2011). Effect of Three Counter measures against the Illegal Crossing of Railway Tracks. Accident Analysis and Prevention, Volume 43, Issue 3.

[9] Delmonte, E. and S. Tong (2011). Improving Safety and Accessibility at Level 29 Crossings for Disabled Pedestrians. Report Number T650. Rail Safety and Standards 30 Board, London, United Kingdom, February 2011.

[10] U.S. Department of Transportation, Federal Railroad Administration (2010). Railroad Trespassing, Vandalism, and Highway-Rail Grade Crossing Warning Device Violation Prevention Strategies. Office of Railroad Safety, December 2010.

[11] Rail Safety and Standards Board (2010). Road-Rail Interface Special Topic Report. April 2010. London, United Kingdom

[12] L. Marradi, A. Albanese, and S. Di-raimondo, RUNE (Railway User Navigation Equipment): Architecture \& Tests, Satellite Communications and Navigation Systems, pp.461-479, 2008.

[13] Y. Zheng, M. Hutchinson, D. Lowe, S. Arrizabalaga, J. Goya et al., The hybrid GNSS/WCT multi-coach multiconstellation train positioning and integrity system Evaluating multiple GNSS data in a multihypothesis based map-matching algorithm for train positioning, Proceedings of the 2016 International Technical Meeting, ION ITM 2016 Intelligent Vehicles Symposium (IV), pp.2011-1037, 2011.

[14] A. Acharya, S. Sadhu, and T. K. Ghoshal, Train localization and parting detection using data fusion, Transportation Research Part C: Emerging Technologies, vol.19, issue.1, pp.75-84, 2011.

[15] J. Wang, X. H. Yan, B. G. Cai, and W. Shangguan, Research on deeply integrated GPS/INS for autonomous train positioning, 2011 4th IEEE International Symposium on Microwave, Antenna, Propagation and EMC Technologies for Wireless Communications, pp.687-690, 2011.

[16] S. S. Saab, A map matching approach for train positioning. I. Development and analysis, Vehicular Technology, pp.467-475, 2000.

[17] J. Liu, B. G. Cai, and J. Wang, A GNSS/trackmap cooperative train positioning method for satellite-based train control, 17th International IEEE Conference on Intelligent Transportation Systems (ITSC), pp.27182724, 2014.

[18] T. Albrecht, K. Luddecke, and J. Zimmermann, A precise and reliable train positioning system and its use for automation of train operation, 2013 IEEE International Conference on Intelligent Rail 
Transportation Proceedings, pp.134-139, 2013.

[19] A. Mirabadi, F. Schmid, and N. Mort, Multisensor Integration Methods in the Development of a FaultTolerant Train Navigation System, The Journal of Navigation, vol.56, issue.3, pp.56-385, 2003.

[20] L. Jiang, C. Bai-gen, T. Tao, and W. Jian, A CKF based GNSS/INS train integrated positioning method, Mechatronics and Automation (ICMA), 2010 International Conference on, pp.1686-1689, 2010.

[21] Ultrasonic sensor image is downloaded from https://www.indiamart.com/proddetail/hc-sr04ultrasonic-sensor-module-19727491430.html.
[22] IR sensor image is downloaded from https://www.amazon.in/VEEROBOT-InfraredProximity-Obstacle-Detecting/dp/B0115NCT4U.

[23] NodeMcu image is downloaded from https://www.elektor.com/nodemcu-microcontrollerboard-with-esp8266-and-lua.

[24] WI-FI module image is downloaded from https://www.electronicscomp.com/esp-12f-esp8266-wifiwirelessmodule?gclid=Cj0KCQjwwOz6BRCgARIsAKE G4FVXIDupzL1msSqhmJNwaOLDPV6V-

2zteMA8W4RSJOJwx0dqkw93m2oaAnISEALw_wcB. 